\title{
Mitochondrial Disorder Associated with Newborn Cardiopulmonary Arrest
}

\author{
KYUNGLIM L. YOON, ${ }^{1}$ SUSAN G. ERNST, CYNTHIA RASMUSSEN, ELIZABETH C. DOOLING, \\ AND JUNE R. APRILLE \\ Mitochondrial Physiology Unit, Department of Biology, Tufts University, Medford, Massachusetts 02155 [K.L.Y., \\ S.G.E., J.R.A.]; and Pediatric Neurology Unit, Massachusetts General Hospital, Boston, Massachusetts 02114
}

[E.C.D.]

\begin{abstract}
A female infant who died $2.5 \mathrm{~d}$ after birth with hypoglycemia, lactic acidosis, and sudden multisystem failure was studied. Biochemical studies showed complex III and IV deficiency in liver, kidney, and muscle, with muscle most severely affected. Southern blot analysis of the patient's mitochondrial DNA did not reveal any deletions. Denaturing gradient gel analysis, which detects single base changes by differences in melting behavior, showed an extra band that was not seen in mitochondrial DNA from the mother, the mother's identical twin sister, or an unrelated normal subject. This extra band indicated heteroplasmy for a restriction fragment containing the apocytochrome $b$ and transfer $\mathbf{R N A}^{\text {thr }}$ genes. Sequencing revealed an $A$ to $G$ mutation at nucleotide 15923 , the last base of the anticodon loop of the transfer RNA ${ }^{\text {thr }}$ gene. The mutation lengthens the anticodon stem by added pairing and reduces the anticodon loop size from 7 to 5 nucleotides, potentially compromising transfer $\mathbf{R N A}^{\text {thr }}$ function in translation and/or in processing the polycistronic RNA transcript. The patient's mother previously had a male infant who also died at $1.5 \mathrm{~d}$ postnatal, and both the mother and her twin have had multiple miscarriages. Amniocentesis for a genetic screen was performed on the mother's twin sister during a recent pregnancy; some of the cultured cells were made available for this study. The mutation was not found in the amniocytes or in umbilical cord blood obtained at birth; the baby was normal at birth and remains healthy. It is concluded that the mutation at nucleotide 15923 was most likely the cause of the fatal disease in the index case. The timing of the illness was consistent with postnatal depletion of glycogen reserves. The findings suggest that a mitochondrial disorder should be considered for infants who experience sudden cardiopulmonary arrest within the first few days of life. (Pediatr Res 33: 433-440, 1993)
\end{abstract}

\section{Abbreviations}

mtDNA, mitochondrial DNA

FIMED, fatal infantile mitochondrial enzyme deficiency nt, nucleotide

DGGE, denaturing gradient gel electrophoresis

DHU, dihydrouridine

PCR, polymerase chain reaction

MBP, melting behavior polymorphism

tRNA, transfer RNA

Received July 14, 1992; accepted December 29, 1992

Correspondence and reprint requests: June R. Aprille, Ph.D., Mitochondrial Physiology Unit, Department of Biology, Tufts University, Medford, MA 02155.

Supported by NIH HD16936, NSF DCB-9009801, and the Charles H. Hood Foundation.

${ }^{1}$ Present address: Biochemistry and Molecular Biology Department, Harvard University, Cambridge, MA 02138.
CoQ, coenzyme $Q$

rRNA, ribosomal RNA

The mitochondrial respiratory chain is composed of four enzyme complexes: complex I (NADH-CoQ oxidoreductase), complex II (succinate-CoQ oxidoreductase), complex III (CoQcytochrome $c$ oxidoreductase), and complex IV (cytochrome $c$ oxidase). The ATP synthetase is complex V. Most respiratory chain defects that manifest clinically occur in respiratory complexes I, III, and IV (1-5); defects in II and V have been reported less frequently. A deficiency of mitochondrial respiratory enzyme activity is the cause of the fatal infantile form of mitochondrial disease, FIMED. A commonly reported form of FIMED is characterized by a myopathy that includes generalized muscle weakness and lactic acidosis with primary or secondary encephalopathy. Some patients have instead, or in addition, hepatopathy, renal dysfunction, and cardiomyopathy. They all usually die before $1 \mathrm{y}$ of age, especially if muscle is involved and if the defect involves cytochrome $c$ oxidase in any of the affected tissues, although reversible courses have been described in a few patients (5).

Deletions and point mutations in mtDNA have been reported in a number of mitochondrial diseases $(5,6)$. Many cases of Kearns-Sayre syndrome, chronic progressive external ophthalmoplegia, Pearson's syndrome, and unclassified mitochondrial myopathies are associated with large deletions of the mitochondrial genome (5). Leber's hereditary optic neuropathy is related to several point mutations in respiratory complexes I and III ( 7 , 8). A mutation in the ATPase subunit 6 gene has been found in another mitochondrial disease (9). At the time of a recent review (5), 17 mitochondrial tRNA point mutations in 11 different tRNA had been found in various mitochondrial disorders. Specific mutations in certain mitochondrial tRNA occur with high frequency in maternally inherited, progressive syndromes such as myoclonus epilepsy and ragged red fibers and mitochondrial myopathy, encephalopathy, lactic acidosis, and stroke-like episodes.

No clear pattern has been established for the cause of FIMED, which comprises a large subset of mitochondrial diseases. The disease is clinically variable depending on which organ dysfunction dominates the picture, and there may be various genetic causes (5). The common endpoint is failure to develop independent aerobic metabolism in newborn life. We previously reported two novel $A$ to $G$ mutations, one in the anticodon stem and one in the anticodon loop of the mitochondrial tRNA ${ }^{\text {thr }}$ gene, in two unrelated patients with FIMED who died 2 to $4 \mathrm{~d}$ after birth (10). The latter case was an unusual form of FIMED, in that the infant appeared normal before sudden cardiopulmonary arrest on $\mathrm{d} 2$ of life. The purpose of this article is to describe 
the clinical, biochemical, and molecular features of this case in greater detail and to report an extension of the mtDNA analysis to family members and to amniocentesis. The findings specifically suggest a causative role for the mitochondrial tRNA ${ }^{\text {thr }}$ mutation in this patient's illness and more generally suggest that a mitochondrial disorder should be considered when precipitous multisystem failure occurs in early postnatal life.

\section{MATERIALS AND METHODS}

Patient description. The index case was a full-term female weighing $3.2 \mathrm{~kg}$, born to a $37-y r-o l d$ woman who was in good health. The baby had an uncomplicated, normal, spontaneous vaginal delivery with Apgar scores of 9 and 9 and was asymptomatic for the first $24 \mathrm{~h}$. She was examined by a cardiologist who found no abnormalities. On the 2 nd d, the mother noticed that the baby had a progressively weak suck and became dusky after the last feeding. At $34 \mathrm{~h}$, she had a sudden respiratory and cardiac arrest, and cardiopulmonary resuscitation was started immediately. She remained in cardiopulmonary arrest intermittently with ongoing cardiopulmonary resuscitation for $2.5 \mathrm{~h}$, at the end of which time there was a sinus rhythm, and she opened her eyes. A transport team found the baby with a heart rate of 180 beats/min; she was hypoglycemic $(30 \mathrm{mg} / \mathrm{dL})$, and her pupils remained dilated and fixed. The baby was transferred to Massachusetts General Hospital and was stabilized on supported respiration. Serum potassium was $8.8 \mathrm{mmol} / \mathrm{L}$ (normal 4 to 6 $\mathrm{mmol} / \mathrm{L}$ ). Serum lactate was $5.0 \mathrm{nmol} / \mathrm{L}$ (normal 0.6 to 1.8 $\mathrm{nmol} / \mathrm{L}$ ); plasma ammonia was $99 \mu \mathrm{mol} / \mathrm{L}$ (normal 12 to 55 $\mu \mathrm{mol} / \mathrm{L}$ ); total plasma carnitine was $57.6 \mu \mathrm{mol} / \mathrm{L}$ (normal 26 to $67 \mu \mathrm{mol} / \mathrm{L}$ ); free/total carnitine was $18 \%$ (normal 70 to $94 \%$ ). A urine screen revealed very high lactate, slightly elevated 3-OHbutyrate, and an unremarkable amino acid pattern. She was treated with $\mathrm{K}$-exylate, bicarbonate, triple pressors, and glucose.

She subsequently required defibrillation twice but had recurrent ventricular tachycardia and then ventricular fibrillation. She was defibrillated again without recovering sinus rhythm. Finally, the patient became asystolic and was pronounced dead at $56 \mathrm{~h}$ of age.

General pathology was unremarkable. Ultrastructural examination of autopsy tissues showed that liver and skeletal muscle were in a moderately preserved state. Mitochondria were qualitatively unremarkable in number, size, morphology, and intracellular distribution, and were judged to be within normal ultrastructural limits.

Family history. The mother's history was notable for five spontaneous abortions and for a male child who died in cardiopulmonary arrest at about $42 \mathrm{~h}$ of life. He was born after an uncomplicated pregnancy and normal spontaneous vaginal delivery with Apgar scores of 9 and 9 . His birth weight was $2.9 \mathrm{~kg}$. At $30 \mathrm{~h}$, he was found apneic in the newborn nursery. He was initially stabilized, but enroute to a medical center he had a cardiopulmonary arrest. He was pronounced dead after $3 \mathrm{~h}$ of resuscitation efforts, including defibrillation. The pathology report noted structural abnormalities in the aorta and aortic valve that were consistent with mild congenital heart disease, but the course of events was identical to that of the sibling who is the index case, and metabolic disease was a question at the time. Newborn blood spots required for organic acid screening can be used for mtDNA analysis, but the boy's blood sample was not obtained because of his sudden decline and transfer to another facility.

The mother has an identical twin sister who also has had several miscarriages. At about the time that we were concluding studies on the index case, the mother's twin became pregnant. Amniocentesis was performed in the 1st trimester for various genetic screens, and extra cultured cells were available for studies of fetal mtDNA.

Suspicion of mitochondrial disease. Metabolic disease, possibly mitochondrial, was investigated in the index case due to a combination of factors, including: 1) a sibling with identical course; 2) fulminant illness without infection or other explanation; 3) elevated lactate, hypoglycemia, and low free/total carnitine ratio; and 4) cardiac arrest and multisystem failure consistent with a time course for postnatal glycogen depletion.

Biochemical analysis. All tissues used in this study were available retrospectively, as remainders from tissues obtained for unrelated pathologic, diagnostic, or surgical/medical purposes. The studies were reviewed and approved on this basis by the Human Studies Committee. For the patient, frozen autopsy tissue was used. Controls were autopsy, biopsy, or surgical tissues that were stored at $-70^{\circ} \mathrm{C}$ from children and young people without evidence of mitochondrial disease. Homogenates and mitochondrial membrane fractions were prepared from frozen liver, kidney, and muscle, as described previously (11). Enzyme activities were assayed spectrophotometrically according to standard methods. Citrate synthetase, a matrix marker enzyme (12), was assayed in homogenates to assess tissue integrity. Succinate-cytochrome $c$ reductase activity, which includes respiratory complex II and III activities, and cytochrome $c$ oxidase activity, which is complex IV, were assayed to assess respiratory chain function (13). Complex I activity was not measured in this patient. Among the controls, there was no significant difference in measured enzyme activities between autopsy and biopsy/ surgical samples (data not shown), so they were treated as one group.

Southern blot analysis of patient's mtDNA. Total cellular DNA was isolated by standard methods from frozen tissues (14). To determine the abundance of mtDNA relative to nuclear DNA, 5 to $10 \mu \mathrm{g}$ of each DNA sample were digested with $P v u \mathrm{II}$, electrophoresed through an $0.8 \%$ agarose gel, and transferred to a nitrocellulose filter. The filter was then hybridized with total human linearized mtDNA and a 1.0-kb EcoRI-BamHI fragment of human 18S rRNA gene (kindly provided by Dr. Simon Waters, University of Massachusetts) that was ${ }^{32} \mathrm{P}$-labeled by random priming as previously described (15).

Hybridization was performed overnight at $65^{\circ} \mathrm{C}$ in a solution containing $10 \times$ Denhardt's solution, $5 \times$ standard saline citrate, $1 \% \mathrm{SDS}$, and $100 \mu \mathrm{g} / \mathrm{mL}$ denatured salmon sperm DNA. Filters were washed three times for $30 \mathrm{~min}$ in a solution containing $1 \times$ standard saline citrate and $1 \% \operatorname{SDS}$ at $65^{\circ} \mathrm{C}$. Films were exposed for $8 \mathrm{~h}$. Before each subsequent hybridization, the probe was removed by boiling the filter in water for $10 \mathrm{~min}$.

Extraction of total DNA from relatives' blood and umbilical cord blood for mtDNA analysis. Ten $\mathrm{mL}$ of blood were obtained from the mother, the mother's twin sister, and her child's umbilical cord. Total DNA was extracted from buffy coats using standard procedures as follows. The cells were lysed with SDS, digested with proteinase $\mathrm{K}$, extracted with phenol followed by chloroform:isoamyl alcohol (24:1), and finally precipitated with ethanol. This crude total DNA was then resuspended in TE buffer (10 mM Tris-HCl, pH 8.0; 1 mM EDTA).

Extraction of total DNA from cultured amniocytes. Cells cultured from amniocentesis were harvested by adding fresh $0.25 \%$ trypsin and centrifuging for $15 \mathrm{~min}$ at $500 \times \mathrm{g}$. After the cells were washed with ice-cold PBS, they were resuspended with lysis buffer (100 mM NaCl; $10 \mathrm{mM}$ Tris-HCl, pH 8.0; 25 mM EDTA, $\mathrm{pH} 8.0 ; 0.5 \% \mathrm{SDS}$; and $0.1 \mathrm{mg} / \mathrm{mL}$ proteinase $\mathrm{K}$ ) and incubated at $37^{\circ} \mathrm{C}$ with shaking for $3 \mathrm{~h}$ in tightly capped tubes. After a 3-h incubation, samples were extracted with an equal volume of phenol. DNA was precipitated by the addition of $2 \mathrm{vol}$ of $100 \%$ ethanol in the presence of 0.2 vol of $10 \mathrm{M}$ ammonium acetate. The yield of DNA $/ 25-\mathrm{cm}^{2}$ culture flask was about $60 \mu \mathrm{g}$.

Analysis of patient liver and muscle mtDNA by DGGE. mtDNA was isolated from mitochondrial fractions that were prepared from frozen autopsied liver and muscle. Twenty-ng aliquots of mtDNA were digested separately with DdeI, HaeIII, $H p h \mathrm{I}$, and $M b o$ II. The mtDNA fragments were analyzed by DGGE as previously described (15). Briefly, fragments were electrophoresed in a $6.5 \%$ acrylamide gel with a 30 to $70 \%$ 
denaturant range $(100 \%$ denaturant $=7 \mathrm{M}$ urea $/ 40 \%$ formamide) for $18 \mathrm{~h}$ at $65 \mathrm{~V}$. After DGGE, the gel was electroblotted onto a nylon membrane and hybridized with ${ }^{32} \mathrm{P}$-labeled human mtDNA clones. The region of the patient's mtDNA corresponding to clone 13 and containing the fragment that migrated differently than control fragments on the same gel was amplified from total DNA by PCR using the primers described below, subcloned, and sequenced as previously described (15). Both strands were sequenced from two different batches of PCR products to confirm the presence of the mutation.

Digestion with AccI to detect the mtDNA mutation in $t R N A^{\text {thr }}$. A DNA fragment corresponding to mitochondrial clone 13 (10) (nt 14956-16053), covering apocytochrome $b$ and tRNA ${ }^{\text {thr }}$, was amplified by PCR from $200 \mathrm{ng}$ of total DNA using two primers: primer A: 5' 16085 GCGGTTGTTGATGGGTGAGT 16066 3'; primer B: 5' 14947 CCACATCACTCGAGACGTAA 14966 $3^{\prime}$. The amplified DNA fragment was digested with AcCl, electrophoresed in a $1 \%$ agarose gel, and transferred to a nitrocellulose filter by Southern blotting. The filter was hybridized with ${ }^{32} \mathrm{P}$ labeled mitochondrial clone 13 and exposed to $\mathrm{x}$-ray film for 8 h (15).

Computer analyses of nucleic acid structure. The human tRNA $^{\text {thr }}$ gene sequence was compared for homology with the published sequence of cow, rat, mouse, Xenopus laevis, Drosophila yakuba, and two species of sea urchin (16-18).

The Zucker program PCFOLD was used to determine probable differences in the secondary structure of the wild type and mutant sequences of the tRNA ${ }^{\text {thr }}$ anticodon loop.

\section{RESULTS}

Biochemistry. Table 1 shows reduced succinate cytochrome $c$ reductase activity ( $6 \%$ of control) and cytochrome $c$ oxidase activity (5\% of control) in mitochondrial membranes prepared from the patient's skeletal muscle. These apparent enzyme deficiencies were not an artifact of differential centrifugation, inasmuch as cytochrome $c$ oxidase activity was decreased to the same extent in whole homogenates (8\% of control) as in the mitochondrial fraction. The lower citrate synthetase activity in the homogenate ( $41 \%$ of control) may reflect loss of tissue integrity, but it could also be due to fewer mitochondria in the patient's muscle. Nevertheless, the citrate synthetase result suggests that the reduced respiratory enzyme activities cannot be attributed entirely to possible loss of tissue integrity, because citrate synthe- tase activity was decreased to a much lesser extent than the respiratory enzyme activities.

In liver mitochondrial membranes, succinate cytochrome $c$ reductase activity was not detectable, and cytochrome $c$ oxidase activity was decreased to $37 \%$ of control (Table 1). Cytochrome $c$ oxidase was decreased to the same extent in liver homogenate (35\% of control). However, for liver, citrate synthetase was decreased to $44 \%$ of control. Therefore, by the same arguments used above for muscle, some of the decrease in cytochrome $c$ oxidase activity might be attributable to loss of tissue integrity. Nevertheless, it is clear that the decrease in succinate cytochrome $c$ reductase activity is an actual deficiency.

For kidney, the data are not as complete, but the respiratory enzyme deficiency does follow the same pattern as seen in liver, in that succinate cytochrome $c$ reductase activity was reduced to a greater extent than cytochrome $c$ oxidase activity (Table 1).

Southern blot analysis of $m t D N A$. By Southern blot analysis of PvuII-digested DNA, no noticeable differences such as deletions or duplications between affected and unaffected subjects in the same maternal line were found when total mtDNA was used as a probe for the mtDNA signal (Fig. 1A). Because mtDNA depletion was reported as one of the causes of FIMED (19), we looked for a quantitative change of mtDNA in this patient. The same genomic blot of PvulI-digested total DNA was hybridized with a nuclear $18 \mathrm{~S}$ rRNA gene probe after stripping the mitochondrial probe from the filter (Fig. $1 B$ ). The ratio of mtDNA to nuclear DNA can be estimated by comparing Figure $1 A$ and $B$. The mother's twin sister, the mother, and the patient all had ratios that were different from an unrelated control but similar to each other. This similarity between the patient and her phenotypically normal relatives rules out mtDNA depletion as a specific cause of the fatal disease in this infant. By electron microscopic study, there was no remarkable morphology or distribution of mitochondria in liver and muscle (data not shown).

Identification of $t R N A^{\text {thr }}$ mutation. By DGGE (15), we found an MBP among $H p h \mathrm{I}$ fragments (shown by the arrow in Fig. $2 B$ ) that were probed with mtDNA clone 13 (Fig. $2 A$ ). This clone covers a portion of the cytochrome $b$ coding region, the tRNA ${ }^{\text {thr }}$ gene, and a portion of the $\mathrm{D}$ loop (Fig. $2 A$ ). With this probe, an extra band just below the major band was detected in the patient but not in the control and not in the mother's twin sister or the mother. This indicates that the patient had both wild type and mutant mtDNA existing in a heteroplasmic state (Fig. $2 B$ ). As

Table 1. Mitochondrial enzyme activities in patient and control tissues*

\begin{tabular}{|c|c|c|c|c|}
\hline & \multicolumn{2}{|c|}{ Homogenate } & \multicolumn{2}{|c|}{ Mitochondrial membranes } \\
\hline & $\begin{array}{c}\text { Citrate } \\
\text { synthetase }\end{array}$ & $\begin{array}{l}\text { Cyt } c \\
\text { oxidase }\end{array}$ & $\begin{array}{l}\text { Succ-cyt } c \\
\text { reductase }\end{array}$ & $\begin{array}{c}\text { Cyt } c \\
\text { oxidase }\end{array}$ \\
\hline \multicolumn{5}{|l|}{ Skeletal muscle } \\
\hline Control activity & $73 \pm 11(9)$ & $334 \pm 62(9)$ & $334 \pm 62(9)$ & $1821 \pm 273(9)$ \\
\hline \multicolumn{5}{|l|}{ Patient } \\
\hline Activity & 30 & 29.6 & 20 & 89 \\
\hline$\%$ control & 41 & 8 & 6 & 5 \\
\hline \multicolumn{5}{|l|}{ Liver } \\
\hline Control activity & $39 \pm 6$ & $174 \pm 18(16)$ & $555 \pm 70(6)$ & $655 \pm 77$ \\
\hline \multicolumn{5}{|l|}{ Patient } \\
\hline Activity & 17 & 60.1 & 0 & 245 \\
\hline$\%$ control & 44 & 35 & 0 & 37 \\
\hline \multicolumn{5}{|l|}{ Kidney cortex } \\
\hline Control activity & ND & ND & $264(1)$ & $1154 \pm 209(4)$ \\
\hline \multicolumn{5}{|l|}{ Patient } \\
\hline Activity & ND & ND & 0 & 292 \\
\hline$\%$ control & ND & ND & 0 & 25 \\
\hline
\end{tabular}

* Controls were autopsy, biopsy, or surgical tissue from children or young people who had no evidence of biochemical enzyme deficiency. Activities are in $\mathrm{nmol} / \mathrm{min} / \mathrm{mg}$ protein in homogenates or mitochondrial membranes. Control values are mean \pm SEM for number of individuals in parentheses. For the patient, \% control is the measured activity as a percentage of mean control values. Cyt $c$, cytochrome $c$; succ-cyt $c$, succinatecytochrome $c$; ND, not done. 


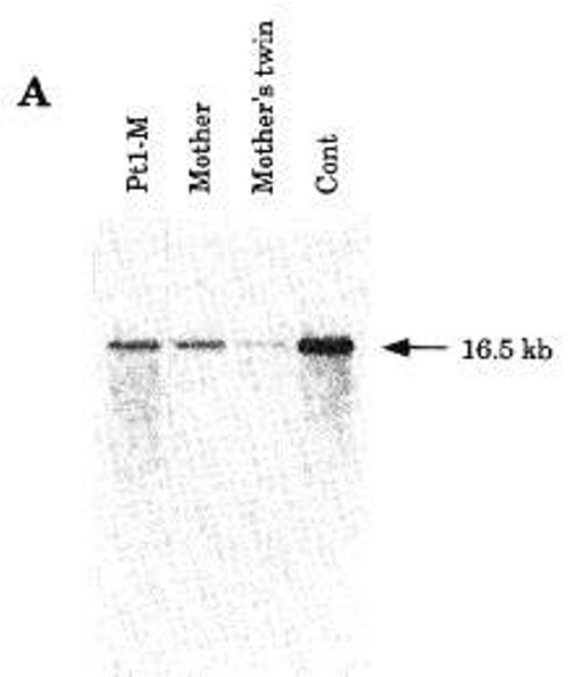

B

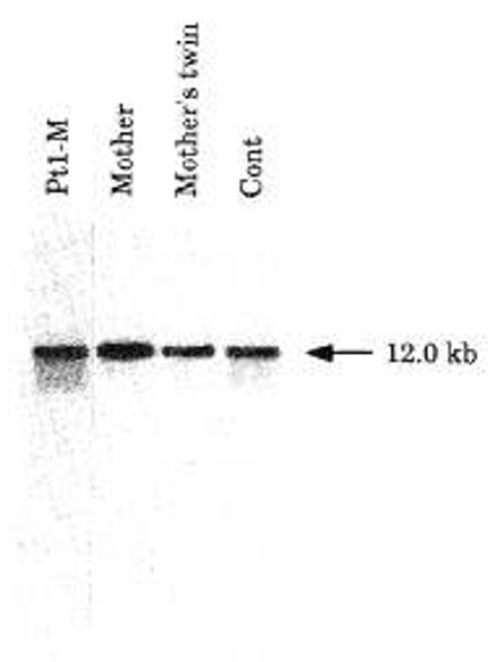

Fig. 1. Southern blot analysis of mtDNA. Total DNA was extracted from normal control liver, patient muscle, and blood from the mother and the mother's twin sister. The total DNA was digested with $P v u$ II, electrophoresed through a $0.8 \%$ agarose gel, transferred to nitrocellulose, and hybridized with ${ }^{32} \mathrm{P}$-labeled total human mtDNA $(A)$ and a ${ }^{32} \mathrm{P}$-labeled human $18 \mathrm{~S}$ rRNA clone $(B)$.

can be seen in Figure $2 B$, it was necessary to overexpose the film to demonstrate the extra band clearly. Because the bands were so close together and because the labeled wild type fragment had saturated the film, it was not possible to quantitate the extent of heteroplasmy by scanning densitometry.

We examined other regions of mtDNA using additional mitochondrial clones that cover almost the entire mitochondrial genome (15). Additional MBP were detected when the migration of patient's mtDNA was compared with the migration of the control DNA. With these other probes, however, a comparison of the patient's and the mother's samples revealed no difference between their electrophoretic patterns (data not shown). This suggests that these additional MBP are probably benign polymorphisms.

The 1.1-kb region of mtDNA corresponding to mitochondrial clone 13 was amplified by PCR from the patient's total DNA, subcloned, and sequenced to determine the specific base changes that account for the MBP. By comparing the sequence of the patient's mtDNA to the published normal human mtDNA sequence (20), an A to G mutation at 15923 was found in the PCR product of the patient's mtDNA (Fig. 3).

The mutated nt in this patient creates an $A c c$ I restriction site (GTAAAC to GTAGAC), which provided an easy way to look for the mutation in family members. The mtDNA region corresponding to clone 13 was PCR-amplified from a biochemically normal control, from the mother's twin sister, and from the mother. When the PCR products were digested with $\mathrm{AccI}$, two fragments ( $829 \mathrm{bp}$ and $309 \mathrm{bp}$ ) were generated in the control and maternal relatives, as expected for wild type mtDNA. However, the PCR product amplified from the patient's liver and muscle mtDNA generated an additional 667-bp fragment that is predicted by the mutation, in addition to the wild type $829-\mathrm{bp}$ and 309-bp fragments (Fig. $4 A$ and $B$ ). Another 162-bp fragment predicted by this mutation is presumed to have migrated off the gel. The results in Figure $4 A$ and $B$ confirm heteroplasmy in the patient but gave no reliable quantitative information, because PCR products are not necessarily produced in proportion to mutant and wild type abundance in the native DNA sample.

Around the time that we found this mutation, the mother's twin sister became pregnant and underwent amniocentesis for routine genetic screens in the 1 st trimester. Total DNA was isolated from extra cultured amniocytes and also from cells recovered after birth from umbilical cord blood. The $1.1-\mathrm{kb}$ region of mtDNA corresponding to clone 13 was amplified by PCR and directly digested with $A c c I$. As seen in Figure $4 C$, the total PCR product from the fetal cells generated only two frag- ments, as expected for wild type mtDNA. Within the limits of detection by these methods, the result suggested that this fetus did not have an $A$ to $G$ mutation at position 15923 .

The mutation is located at the last base of the anticodon loop of $\mathrm{tRNA}^{\mathrm{thr}}$ (Fig. $5 \mathrm{~A}$ ). The $\mathrm{nt}$ sequences of mtDNA from different organisms were aligned to compare conservation of the genes for tRNA $^{\text {thr }}$ in the anticodon loop region (Fig. $5 B$ ). Nt A at position 15923 was found to be highly conserved among various eukaryotic mtDNA, suggesting that this nt is functionally very significant. By inspection, the mutation has the potential to lengthen the anticodon stem by as many as 2 additional bp; however, computer analysis of secondary structure, which takes energy considerations into account, revealed that only 1 additional bp is probable. This would reduce the anticodon loop size from 7 to $5 \mathrm{nt}$.

\section{DISCUSSION}

The index case in this family had an $A$ to $G$ mutation at $n t$ 15923 in the tRNA ${ }^{\text {thr }}$ gene of liver and muscle mtDNA. The mutation was not detected as a polymorphism among 183 control subjects $(21)$, nor was it present in three asymptomatic maternal relatives. Therefore, the mutation is a strong candidate as the cause of the patient's mitochondrial enzyme deficiency and fatal illness.

Computer analysis of tRNA secondary structure suggests that this mutation will lengthen the anticodon stem by at least $1 \mathrm{bp}$, thereby reducing the anticodon loop size from 7 to $5 \mathrm{nt}$. The conformation of a 7-bp anticodon loop is conserved in tRNA of all species, probably for maximum accuracy of the 3-bp codon reading function. It is known that the most conserved regions of a tRNA molecule are the anticodon loop, anticodon stem, the $\mathrm{DHU}$ stem, and the aminoacyl acceptor, whereas the $\mathrm{T} \phi \mathrm{C}$ and DHU loop and the extra arm are the least conserved (22). Therefore, the mutation at nt 15923 is likely to impair tRNA ${ }^{\text {thr }}$ anticodon function, blocking translation with high frequency and resulting in low efficiency of protein synthesis. Respiratory complexes III and IV both contain mitochondrial translation products, and enzyme activities involving these respiratory complexes were decreased in the index case, although not uniformly. Complex III was affected to a greater extent than complex IV, and both were affected to different extents in different tissues.

It has been shown that aminoacyl tRNA synthetase recognition of its cognate tRNA is extremely specific and can be affected by even a single base change in the tRNA (23). Alterations that change the configuration of the secondary and tertiary structure of the anticodon loop may reduce affinity of the synthetase for 

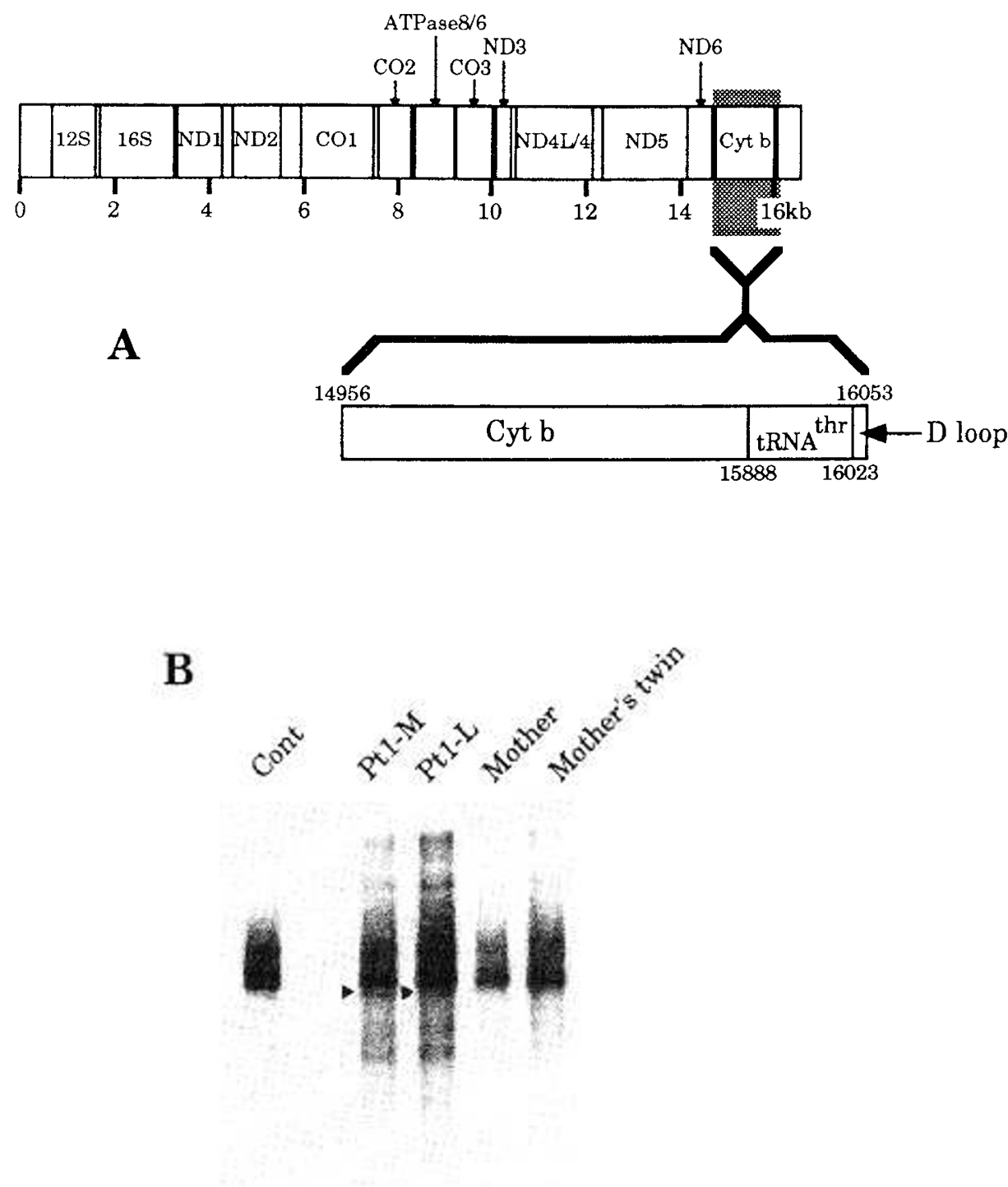

Fig. 2. A, diagram of the linearized human mitochondrial genome. The dotted region was used as the mtDNA probe in denaturing gradient gel analysis. The lower right panel shows an expanded map of the probe. The numbering is according to Anderson $e t$ al. (20). $B$, denaturing gradient gel analysis of human mtDNA from liver of control (Cont), patient muscle (Pt $1-M)$, patient liver (Ptl-L), and blood of the mother and the mother's twin sister. The Hphl enzyme-digested mtDNA were electrophoresed in a 30 to $70 \%$ denaturing gradient gel and hybridized with the probe shown in $A$. The arrows indicate the heteroplasmic fragment in the patient.

the tRNA molecule, but the effect on protein synthesis would depend on the amount of wild type tRNA available for complementation in the same organelle. Another formal possibility is that the mutant $\mathrm{tRNA}^{\text {thr }}$ could be recognized by the wrong synthetase, thus inserting an inappropriate amino acid into the protein sequence, but this seems unlikely.

Recently, it was reported that 16 S rRNA transcriptional termination is severely impaired by a point mutation at nt 3243 in tRNA $^{\text {leu(UUR) }}$ that is associated with mitochondrial myopathy, encephalopathy, lactic acidosis, and stroke-like episodes, suggesting that an inappropriate ratio of rRNA and mitochondrial protein gene products might be involved in the pathogenesis (24). The mutation in our patient's tRNA ${ }^{\text {thr }}$ might similarly affect a proximal controlling region for transcription and/or for mRNA processing in addition to more general effects on translation noted above. Complex III was affected more consistently and more severely than complex IV in this patient, possibly because the cytochrome $b$ mRNA is adjacent to tRNA ${ }^{\text {thr }}$, which is a processing site in the polycistronic message (25).

An interesting question is the mechanism by which the tRNA mutation can lead to a variable expression of enzyme deficiency in different tissues. One possible explanation is a variable distribution of mutant mtDNA among mitochondria or among cells, which would result in heterogeneity and a variable complementation effect of wild type tRNA. Intercellular and intracellular heterogeneous populations of mtDNA were found in a patient 


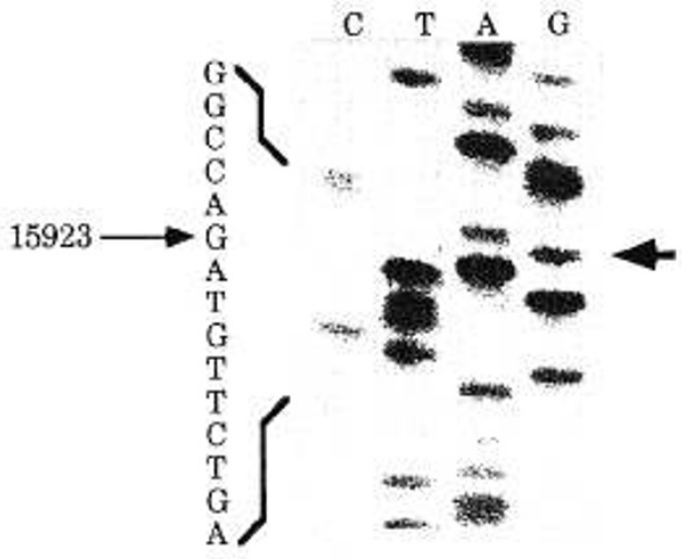

Fig. 3. Autoradiograph of the sequencing gel showing an $A$ to $G$ transition mutation of the mitochondrial tRNA ${ }^{\text {thr }}$ gene at nt 15923 in the patient. The sequencing was carried out on a cloned PCR product corresponding to the probe shown in Figure $2 A$.

with fatal infantile mitochondrial myopathy by electron microscopic study (26). However, with few exceptions, the magnitude of enzyme deficiencies in various tissues is not well correlated with the extent of measurable mtDNA heteroplasmy or even with clinical severity of the mitochondrial disease (5). Qualitatively, heteroplasmy was similar in our patient's liver and muscle, yet the biochemical enzyme deficiency was much greater in muscle, a difference that remains unexplained.

The mother had a normal phenotype; the mutation and respiratory chain deficiency appeared only in her progeny. The identical twin sister in theory could have a dissimilar mitochondrial genotype because of unequal distribution of mitochondria during fission, but neither the patient's mother nor the mother's twin sister had the mutation in somatic tissue (blood). Heteroplasmy in the patient suggests that the detrimental mutation may have existed in the germ line or may have arisen during oogenesis and thereby was inherited from a phenotypically normal mother. Alternatively, it may have arisen during early embryogenesis. The fact that a previous child died with a similar course suggests a defective germ line, because a spontaneous disease is unlikely to have occurred twice. However, without access to mtDNA from this sibling, it is not possible to know if the mutation was present. The comparable degree of heteroplasmy in liver and muscle found in the patient also supports the occurrence of a maternal mutation in the germ line.

Hauswirth and Laipis (27) demonstrated that one genotype of mtDNA could switch completely to another genotype in a single generation because the number of mtDNA in one organelle can be reduced remarkably during oogenesis. If variable heteroplasmy characterizes the mother's germ line, some fetuses could have been more affected than others, contributing to the variable timing of miscarriage. The index case developed normally to full term, perhaps because she had a relatively small proportion of mutant to wild type mtDNA. However, because there is no direct evidence of mtDNA mutation in the mother or her identical twin, it is possible that the frequent history of miscarriages and difficult conception in these women may be due to another familial factor.

The extension of mtDNA analysis to amniocytes and umbilical blood cells led to the conclusion that the child of the mother's twin sister does not have the mutation. Although not diagnostic, the result was encouraging for the family because neither of the twin sisters had ever produced a child that survived. However, caution must be exercised in interpreting such results, because mtDNA in cultured amniocytes and blood cells may not be representative of mtDNA in cells of critical fetal organs. Also, a small percentage of heteroplasmy could be missed due to limitations in sensitivity of the methods used to detect mutations. Finally, there is always the possibility that the mutation we found
$\mathbf{A}$

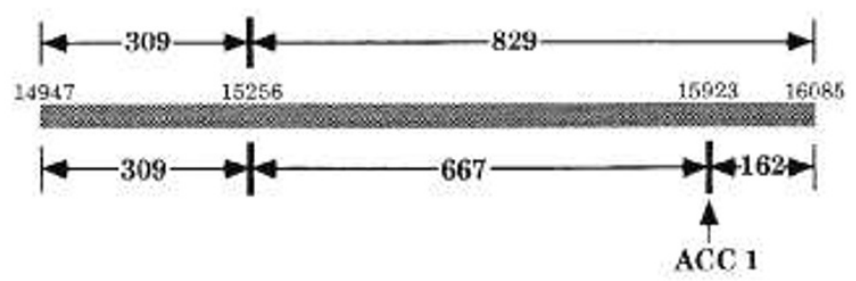

B

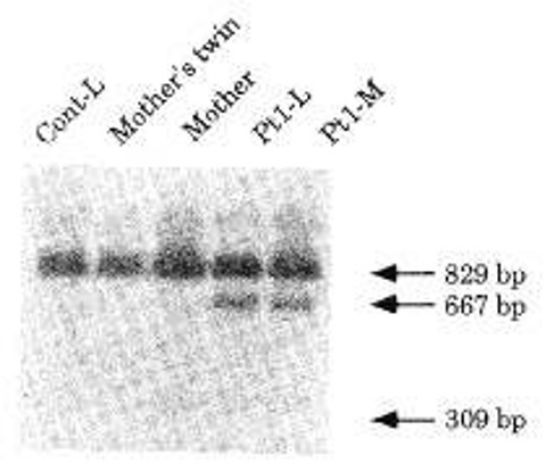

C

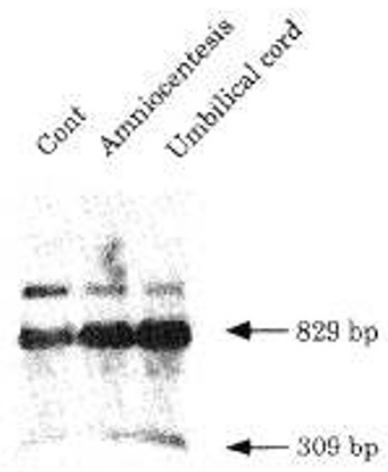

Fig. 4. Detection of the tRNA ${ }^{\text {thr }}$ gene mutation at nt 15923 by $A c c$ I digestion. $A$, The bracketed arrows show that the 1.1-kb PCR amplified fragment from the wild type mtDNA will generate two fragments upon digestion with AccI (top line), whereas the same enzyme digestion of mutant mtDNA will generate three fragments due to the additional $A c c \mathrm{I}$ site indicated by the vertical arrow at nt 15923 (bottom line). $B$, Southern blot of $A c c$-digested PCR products from the liver of a normal control (Cont- $L$ ), the blood of the mother's twin sister and the mother, the patient's liver (Pt1-L), and the patient's muscle (Pt1-M). The patient's mtDNA generated a 667-bp fragment predicted by the mutation in addition to the wild type 829-bp fragment. $C$, Digested PCR products from fetal cells (amniocentesis) and from umbilical cord blood, showing that the mutation was absent. The upper band found in all lanes represents uncut DNA.

in the index case was not the primary cause of illness and death. As of this writing, the twin's child remains healthy.

The patient was the product of uneventful gestation and birth, but she apparently could not sustain independent aerobic metabolism sufficient to meet energy demands after birth. There may be little selection against defective mitochondria during gestation, because fetal tissues are relatively hypoxic, glucose is not limiting, and lactate is cleared by maternal circulation. After birth, aerobic metabolism becomes essential for survival. A recent review considers in detail the special problems that are faced by newborns with mtDNA mutations that cause acute mitochondrial disease in the postnatal period (5). The term infant normally has large carbohydrate stores in liver and heart that are deposited late in 
A

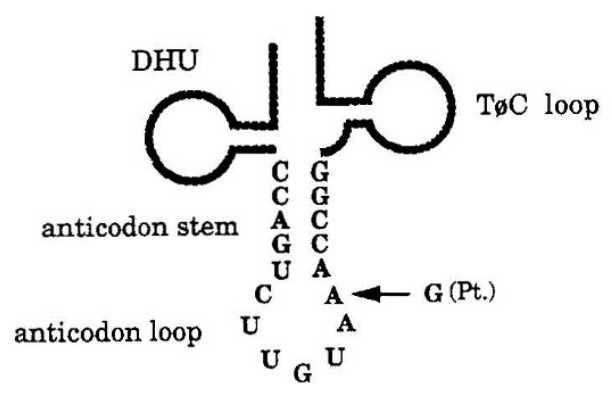

B

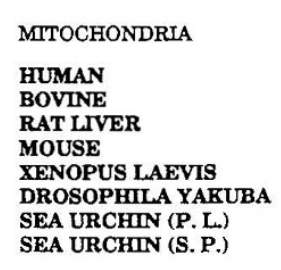

anticodon stem | anticodon loop | anticodon stem

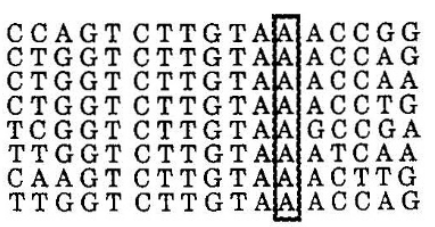

Fig. 5. The $\mathrm{RRNA}^{\mathrm{thr}}$ position 15923 mutation and its interspecies homology. $A$, The arrow in the diagram of $\mathrm{RNNA}^{\mathrm{thr}}$ in the upper panel shows the position of the A to $\mathrm{G}$ mutation in the anticodon loop found in the patient (Pt.). B, an A to G mutation at nt 15923 alters a highly conserved adenine that is the last base of the anticodon loop of tRNA ${ }^{\text {thr }}$. Position 15923 is indicated by the box in the sequence alignments (1618).

gestation. The ability of newborn animals to tolerate hypoxia is correlated with the initial glycogen content; in humans, newborn heart failure is associated with hypoglycemia (28). A mitochondrial enzyme deficiency is energetically similar to hypoxia, because it forces a reliance on glycolysis for ATP synthesis and will result in glycogen utilization, lactic acidosis, and eventual hypoglycemia. These appear to be the consequences suffered by our patient. She was normal at birth, gradually became weaker at 24 to $32 \mathrm{~h}$ of age, and then suddenly had cardiopulmonary arrest at $34 \mathrm{~h}$, a time frame consistent with postnatal glycogen depletion $(28,29)$. Her condition could not be corrected with glucose infusion to promote further glycolysis, a situation that is also typical of hypoxia-related heart failure (29). There appears to be a mismatch between large energy demands and the rate of glycolytic ATP production in the heart that can be fatal when glycogen reserves are exhausted.

We recently reported (10) a homoplasmic mutation in $\mathrm{tRNA}^{\mathrm{thr}}$ (at nt 15924) that was associated with FIMED in an infant who was born prematurely and died on d 4. A mutation at nt 15924 enlarges the anticodon loop size, and presumably normal translation can still occur with some frequency $(10,30)$. The same mutation was found in another fatal case (21). However, it was also present in the asymptomatic mother in our case (data not shown) and in the other case (21), and it occurs with a frequency of about $11 \%$ in control subjects (21). Therefore, this mutation alone cannot account for FIMED, but it might have a contributing role in combination with other risk factors that cause energy stress (5). The patient that we studied (10) experienced an hypoxic episode in utero in addition to premature birth, and therefore she probably did not have significant glycogen reserves.

It is becoming clear that FIMED can have many genetic causes (15). The common endpoint is early postnatal death, but each case may represent a different mutation, variable heteroplasmy, and variable tissue involvement. In addition, there may be physiologic factors unrelated to the mutation (such as transient hypoxia) that affect chances of survival (5). The case presented in this study calls attention to the possibility of mitochondrial disorder in infants who develop unheralded cardiopulmonary arrest in the first day or two of life. Patients in this subset of mitochondrial disease are unlikely to have a common causative mutation. The technique of DGGE used here lends itself well to the analysis of such patients and their families, because unique point mutations can be detected without sequencing the entire mitochondrial genome.

Acknowledgments. The authors thank Dr. Barbara Centes for the pathology report of the electronmicroscopic study of patient tissues, Dr. Barbara West for amniocentesis cells, Alec Gross for technical assistance, and the family of the patient for their interest and cooperation.

\section{REFERENCES}

1. Aprille JR 1985 Tissue specific cytochrome deficiencies in human infants. In: Quagliariello E, Slater EC, Palmieri F, Saccone C, Kroon AM (eds) Achievements and Perspectives of Mitochondrial Research, Vol II: Biogenesis. Elsevier, Amsterdam, pp 465-476

2. Petty RKH, Harding AE, Morgan-Hughes JA 1986 The clinical features of mitochondrial myopathy. Brain 109:915-938

3. Arts WFM, Scholte HR, Loonen MCB, Przyrembel H, Fernandes J, Trijbels JMF, Luyt-Houwen IEM 1987 Cytochrome $c$ oxidase deficiency in subacute necrotizing encephalomyelopathy. J Neurol Sci 77:103-115

4. Birch-Machin MA, Shephard IM, Watmough NJ, Sherratt HSA, Bartlett K, Darley-Usmar VM, Milligan DWA 1989 Fatal lactic acidosis in infancy with a defect of complex III of the respiratory chain. Pediatr Res 25:553-559

5. Aprille JR 1991 Mitochondrial cytopathies and mitochondrial DNA mutations. Curr Opin Pediatr 3:1045-1054

6. Lander ES, Lodish H 1990 Mitochondrial diseases: gene mapping and gene therapy. Cell 61:925-926

7. Brown MD, Voljavec AS, Lott MT, Torroni A, Yang C-C, Wallace DC 1992 Mitochondrial DNA complex I and III mutations associated with Leber's hereditary optic neuropathy. Genetics 130:163-173

8. Johns DR, Neufeld MJ 1991 Cytochrome $b$ mutations in Leber's hereditary optic neuropathy. Biochem Biophys Res Commun 181:1358-1364

9. Holt IJ, Harding AE, Petty RKH, Morgan-Hughes JA 1990 A new mitochondrial disease associated with mitochondrial DNA heteroplasmy. Am J Hum Genet 46:428-433

10. Yoon KL, Aprille JR, Ernst SG 1991 Mitochondrial tRNA ${ }^{\text {thr }}$ mutation in fatal infantile respiratory enzyme deficiency. Biochem Biophys Res Commun 176:1112-1115

11. Boustany RN, Aprille JR, Halperin J, Levy H, DeLong GR 1983 Mitochondrial cytochrome deficiency presenting as a myopathy with hypotonia, external opthalmoplegia, and lactic acidosis in an infant and as a fatal hepatopathy in a second cousin. Ann Neurol 14:462-470

12. Srere PA 1969 Citrate synthase. Methods Enzymol 13:3-9

13. Misumoto H, Aprille JR, Wray SH, Nemni R, Bradley WG 1983 Chronic progressive external opthalmoplegia (CPEO): clinical, morphologic, and biochemical studies. Neurology 33:452-461

14. Davis LG, Dibner MD, Battey JF 1986 Basic Methods in Molecular Biology. Elsevier, New York, pp 47-50

15. Yoon KL, Modica-Napolitano JS, Ernst SG, Aprille JR 1991 Denaturing gradient gel method for mapping single base changes in human mitochondrial DNA. Anal Biochem 196:427-432

16. Sprinzl M, Gauss DH 1984 Compilation of sequences of tRNA genes. Nucleic Acids Res 12(suppl):r59-r131

17. Clary DO, Wolstenholme DR 1983 Nucleotide sequence of a segment of Drosophila mitochondrial DNA that contains the genes for cytochrome $c$ oxidase subunits II and III and ATPase subunit 6. Nucleic Acids Res $11: 4211-4227$

18. Cantatore P, Roberti M, Rainaldi G, Gadaleta MN, Saccone C 1989 The complete nucleotide sequence, gene organization, and genetic code of the mitochondrial genome of Paracentrotus lividus. J Biol Chem 264:1096510975

19. Moraes CT, Shanske S, Tritschler HJ, Aprille JR, Andreetta F, Bonilla E, Schon EA, Dimauro S 1991 MtDNA depletion with variable tissue expression: a novel genetic abnormality in mitochondrial diseases. Am J Hum Genet 48:492-501

20. Anderson S, Bankier AT, Barrell BG, deBrujin MHL, Coulson AR, Drouin J, Eperon IC, Nierlich DP, Roe BA, Sanger F, Schreier PH, Smith AJH, Staden $\mathrm{R}$, Young IG 1981 Sequence and organization of the human mitochondrial genome. Nature 290:457-465

21. Brown MD, Torroni A, Shoffner JM, Wallace DC 1992 Mitochondrial tRNA $^{\text {thr }}$ mutations and lethal infantile mitochondrial myopathy. Am J Hum Genet 51:446-447

22. Attardi G 1985 Animal mitochondrial DNA: an extreme example of genetic economy. Int Rev Cytol 93:93-145

23. Schimmel PR 1977 Aminoacyl-tRNA synthetases: general features and recognition of transfer RNAs. Annu Rev Biochem 48:601-648

24. Hess JF, Parisi MA, Bennett SL, Clayton DA 1991 Impairment of mitochondrial transcription termination by a point mutation associated with the MELAS subgroup of mitochondrial encephalopathies. Nature 351:236-239 
25. Attardi G, Chomyn A, King MP, Kruse B, Polosa PL, Murdter NN 1990 Biogenesis and assembly of the mitochondrial respiratory chain: structural, genetic and pathological aspects. Biochem Soc Transact 18:509-513

26. Haginoya K, Miyabayashi S, Iinuma K, Tada K 1990 Mosaicism of mitochondria in mitochondrial myopathy: an electron microscopic analysis of cytochrome $c$ oxidase. Acta Neuropathol 80:642-648

27. Hauswirth WW, Laipis PJ 1985 Transmission genetics of mammalian mitochondria: a molecular model and experimental evidence. In: Quagliariello E, Slater EC, Palmieri F, Saccone C, Kroon AM (eds) Achievements and
Perspectives of Mitochondrial Research, Vol II: Biogenesis. Elsevier, Amsterdam, pp 49-60

28. Amatayakul O, Cumming GR, Haworth JC 1970 Association of hypoglycemia with cardiac enlargement and heart failure in newborn infants. Arch Dis Child 45:717-720

29. Lees MH 1980 Perinatal asphyxia and the myocardium. J Pediatr 96:675-678 30. Zheng X, Shoffner JM, Lott MT, Voljavec AS, Krawiecki NS, Winn K, Wallace DC 1989 Evidence in a lethal infantile mitochondrial disease for a nuclear mutation affecting respiratory complexes I and IV. Neurology 39:1203-1209

\section{Announcement}

\section{2nd World Congress of Perinatal Medicine}

The 2nd World Congress of Perinatal Medicine, organized by the World Association of Perinatal Medicine in cooperation with the Italian Society of Perinatal Medicine, will be held in Rome, Italy, September 19 to 24, 1993. Physicians, scientists, nurses, midwives, and others interested in maternal, fetal, and neonatal care, either research or its clinical applications, are invited to attend. Among the topics that will be discussed are technology advances, fetal diagnosis and treatment, infections, care of the extremely premature infant, ethical issues, and family planning. Numerous national and international organizations are collaborating on the 2nd World Congress, including the International Clearinghouse for Birth Defects Monitoring and the March of Dimes Birth Defects Foundation, the Society for Perinatal Obstetricians, and the World Health Organization. The March of Dimes will sponsor a symposium on birth defects entitled "Interventions" on Tuesday, September 21, and speakers will be Michael Blaese, M.D., The National Institutes of Health (recombinant DNA technology and gene therapy in the treatment of birth defects); Daniel Cohen, M.D., The French Genome Project (implications of the Human Genome Project for prevention of birth defects); Stanley Plotkin, Pasteur-Merrieux (vaccines of the future); and Larry Shapiro, M.D., the University of California, San Francisco (nongenetic therapy for birth defects). All scientific sessions and exhibitions will be held at the Citta Universita "La Sapienza" in Rome. The deadline for registration is July 1, 1993. For more information, contact one of the following: Michele Kling, (914) 997-4613, Marcia C. Stein (914) 997-4640, or Andrea Heller Ziltzer (914) 997-4622. 